\title{
Seroprevalence and risk factors for herpes simplex virus type I and 2 among women attending antenatal and gynecology clinics in Sana'a City- Yemen
}

\begin{abstract}
Herpes simplex virus (HSV) infection is one of the worldwide infections. HSV-1 causes herpes labial and HSV-2 is the main cause of genital ulcer. Host's immune response to HSV defines by the presence of neutralizing antibodies to HSV in serum of newly and previously infected persons. A cross-sectional study was designed to determine the prevalence of HSV antibodies and potential risk factors of HSV infections among women attending some hospitals and health centers in Sana'a city based on type-specific serological assay. HSV-1 differs from HSV-2 by the type-specific enveloped glycoprotein $\mathrm{G}(\mathrm{gG})$. This is the base of type-specific ELISA, which is more accurate than ELISA using common antigens. In our knowledge, there are no previous published studies or recorded data regarding the seroprevalence of HSV in Yemen. Moreover, there is no guideline of diagnosis or treatment of HSV infections in women; especially pregnant women. A total of 315 women, including 235 sexually transmitted infections (STIs) patients, 48 herpes labial patients (HLP) and 32 apparently healthy women were enrolled in this study. Of the studied women, 307 were married and 8 were single, their ages range from 14-49 years. Among married women; 53 were pregnant. The total seroprevalence was $2.5 \%$ for HSV IgM, 99.4\% for HSV-1 IgG and $5.1 \%$ for HSV-2 IgG. There were statistically non-significant association between herpes infections and age, size of family, educational level, residence, marital status, pregnancy, abortion, blood transfusion and contraceptive use. In conclusion, the prevalence of HSV1 antibodies was much higher than that of HSV-2. The prevalence of HSV-1 antibodies was higher than those reported in other countries which could be due to poor hygienic conditions in Yemen. The prevalence of HSV-2 antibodies was lower than those reported in other studies; which is probably due to the differences in sexual practices among these cultures.
\end{abstract}

Keywords: HSV-1, HSV-2, HLP, STIs, HSV IgG, HSV IgM, Glycoprotein G, Antenatal Clinics, Yemen
Volume 5 Issue 4 - 2017

Rowa M Assayaghi, Ahmed Y Al-Jaufy, Abdulbaki A Al-Robasi

Department of Medial Microbiology and Immunology, Sana'a University, Yemen

Correspondence: Rowa M Assayaghi, Department of Medial Microbiology and Immunology, Sana'a University, Yemen, Tel 967777259096,Email rowamohammed2010@yahoo.com

Received: April 06, 2017 | Published: May 26, 2017

\section{Introduction}

Infection with herpes simplex virus (HSV) is extremely common and widespread occurring in a worldwide distribution. Herpes virus infections are caused by the two distinct antigenic types; herpes simplex virus type-1 (HSV-1) and herpes simplex virus type-2 (HSV-2). They show a wide variety of clinical manifestations from recognizable symptomatic diseases to sub-clinical and symptomatic infections. ${ }^{1}$ HSV has been implicated in human infection since description of cutaneous spreading lesions in ancient Greek time. Scholars of Greek defined the word herpes to mean "to creep or crawel" in reference to the spreading nature of the observed skin lesions. ${ }^{1}$ There are no known animal vectors and human appears to be the only natural reservoir. Direct contact with infected secretions is the principle mode of spread. HSV has the ability to recur in the presence of humoral immunity- a characteristic known as reactivation of latent infection. ${ }^{2}$ Effective antiviral drugs are developed and are widely used. HSV infection is common in women of reproductive age it can be transmitted and contracted to the fetus during pregnancy and the newborn. Moreover, HSV is an important cause of neonatal infection, which can lead to death or long-term disabilities. Also HSV infection in non-pregnant women may lead to lesions on face and genitalia and spreading virus to others by direct or sexual contact. ${ }^{3}$ In our knowledge, there are no previous published studies or recorded data regarding the seroprevalence of HSV in Yemen. Therefore, there is no guideline of diagnosis or treatment of HSV infections in women; especially pregnant women in hospitals or health centers in Yemen. Laboratory diagnosis can be confirmed by virus isolation in cell culture or by deoxyribonucleic acid (DNA) detection. Serological assays that distinguish between antibodies to HSV-1 and HSV-2 have been developed and are commercially available. ${ }^{3}$ In our study, determination of the prevalence of HSV antibodies and potential risk factors of HSV infections among women attending some hospitals and health centers in Sana'a city based on type-specific serological assay was carried out.

\section{Subjects and methods}

\section{Study area}

The study was conducted in antenatal and gynecology clinics in the main hospitals, health centers and some private clinics in Sana'a city-Yemen.

\section{Study design and population}

A total of 315 women who attended antenatal and gynecology clinics at age of 14-49 years old were enrolled in this study. These women came to these clinics for pregnancy check-up; follow birth 
control program or seeking treatment of some health issues. Target women comprised three groups; herpes labial patients (HLP), sexually transmitted infected patients (STIP) and apparently healthy women who had not any of previous symptoms. All studied women consented to participate in this research project either by verbal agreement or by sign the consent form.

\section{Data collection}

Data was collected in a cross-sectional study. Women with clinical pictures compatible with herpes labial and sexual transmitted infections such as genital ulcer, vaginal discharge, itching, vesicles or lesions on genitalia and redness were included. Pregnant women and women who have no history of genital ulcer or evidence of sexual transmitted infections were also included as apparently healthy women. Women less than 14 and over 50 years old were excluded because they are sexually non-active. All selected groups had clinical examinations by the gynecologist; specific symptoms were diagnosed and questionnaires were taken from every woman.

\section{Sample collection}

Five $\mathrm{mL}$ of venous blood was collected from each subject into a plain container. Then serum was separated from clotted blood and kept at $-20^{\circ} \mathrm{C}$ until used.

\section{Serological assay}

Stored sera were tested for the presence of $\operatorname{IgM}$ and IgG class antibodies to HSV-1 and HSV-2 by Enzyme linked Immunosorbent assay (ELISA) (Biokit, Spain) according to the manufnturer's instructions. Biokit ELISA HSV IgM (immunocapture) was used for detection of IgM antibodies to Herpes Simplex Virus (HSV-1 and HSV-2) while Biokit ELISA HSV-1 IgG and ELISA HSV-2 IgG were used for qualitative detection of $\operatorname{IgG}$ antibodies to Herpes Simplex Virus $1 \& 2$ in human serum.

\section{Statistical analysis}

The statistical analysis of the data was analyzed by using the Social Package of Statistical Science program (IBM SPSS 23, 2015). The significance of differences in proportions was analyzed by $\mathrm{T}$ and Chi-square tests. $\mathrm{P} \leq 0.05$ was considered statistically significant.

\section{Results}

A total of 315 women of childbearing age were enrolled into the study for the detection of anti-HSV antibodies. Seroprevalence of HSV IgM was $2.5 \%, 99.4 \%$ for HSV- $1 \mathrm{IgG}$ and $5.1 \%$ for HSV-2 IgG (Figure 1). (Table 1) represents the distributions of subjects according to general characteristics. The age of women ranges from 14-49 years, $108(34.3 \%)$ at the age of $14-24,135(42.9 \%)$ at the age of $25-35,60$ $(19 \%)$ at the age 36-46 and $12(3.8 \%)$ were more than 46 years old. $307(97.5 \%)$ were ever married and $8(2.5 \%)$ were single. According to the residence, $235(74.6 \%)$ were from urban while $80(25.4 \%)$ were from rural areas. Regarding the level of education, 167 (53\%) were of middle educational level, $126(40 \%)$ were illiterate and $22(7.0 \%)$ were at high educational level. Regarding the clinical diagnosis; 235 $(74.6 \%)$ had ever one symptom of sexually transmitted infections (STIs), 48 (15.2\%) were herpes labial patients (HLP) and $32(10.2 \%)$ were healthy women. Out of 307 married women, 53 (17.3\%) were pregnant and $254(82.7 \%)$ were non-pregnant women (Table 1). The prevalence of HSV IgM was $2.6 \%$ among sexual transmitted infected patients (STIP) group, $6.3 \%$ in healthy group, with no HSV IgM antibodies among the HLP group. 99.6\% STIP were positive for HSV$1 \mathrm{IgG} ; 97.9 \%$ and $100 \%$ were positive for HSV-1 IgG in HLP and healthy groups, respectively. $4.3 \%$ of STIP, $8.3 \%$ of HLP and $6.2 \%$ of healthy women were positive for HSV-2 IgG. Statistically nonsignificant $(\mathrm{P}>0.05)$ association was found between prevalence of HSV antibodies and the clinical diagnosis of women (Table 2). As shown in (Table 2), the pregnant women had no HSV IgM, while the seroprevalence of HSV IgM among non-pregnant women was 3.1 $\%, \mathrm{P}=0.2$. The seroprevalence of HSV-1 IgG among pregnant and non-pregnant women was $98.1 \%$ and $99.6 \%$ respectively, $\mathrm{P}=0.3$. The seroprevalence of HSV-2 IgG in pregnant women was $1.9 \%$, while in non-pregnant women it was $5.9 \%, \mathrm{P}=0.2$ (Table 2). As seen in (Table 2); high prevalence of HSV IgM $8.3 \%$ was in the age group more than $46, \mathrm{P}=0.1$ and high prevalence of $\mathrm{HSV}-2 \mathrm{IgG}$ was $8.1 \%$ in the age group of $25-35, \mathrm{P}$ value 0.08 . The prevalence of HSV-1 IgG in all age groups was similar to some extent, $\mathrm{P}=0.6$. Married women had seroprevalence of HSV IgM $2.6 \%$, while single women were all negative for HSV IgM antibodies, $\mathrm{P}=0.6$. HSV-1 IgG among single women was $100 \%$, while among married group it was $99.3 \%, \mathrm{P}=$ 0.8 . The prevalence of HSV-2 IgG among married women was $5.2 \%$ while single women were all negative for HSV-2 IgG antibodies, $\mathrm{P}$ value 0.5 (Table 2). seroprevalence of HSV IgM, HSV-1 IgG and HSV-2 IgG of women at higher educational level were $0 \%, 100 \%$ and $4.5 \%$, respectively, $\mathrm{P}=0.6$. Prevalences of HSV IgM, HSV- $\mathrm{IgG}$ and HSV-2 IgG of women at middle level of education were $2.4 \%, 100 \%$ and $6.6 \%$, respectively, $\mathrm{P}=0.2$. While, the prevalence of HSV IgM, HSV-1 IgG and HSV-2 IgG antibodies of illiterate group were $3.1 \%$, $98.4 \%$ and $3.1 \%$ respectively, $\mathrm{P}=0.4$ (Table 2 ). The seroprevalence of HSV IgM antibodies among women lived in urban as well as in rural areas was similar $(2.5 \%), \mathrm{P}=0.9$. Women lived in urban area were $99.2 \%$ positive for HSV-1 IgG, while women lived in rural area were positive for $100 \%$ of HSV-1 IgG, $\mathrm{P}=1.0$. The seroprevalence of $\mathrm{HSV}-2 \mathrm{IgG}$ for women lived in urban and rural areas were $5.9 \%$ and $2.5 \%$ respectively, $\mathrm{P}=0.2$ as other tables.

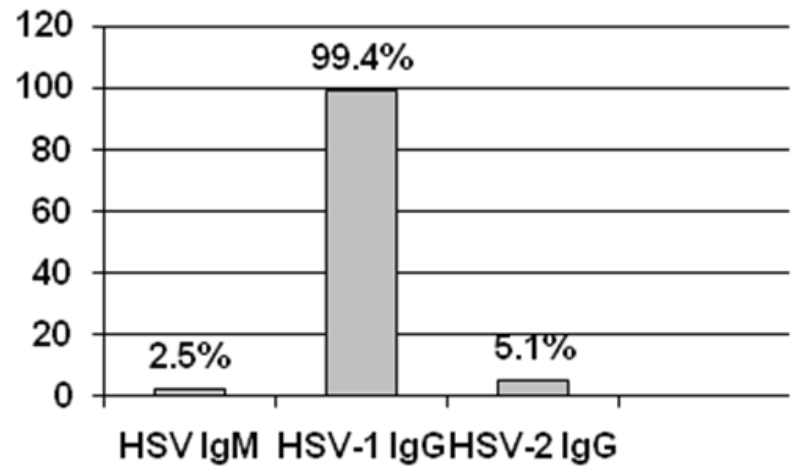

Figure I Total prevalences of HSV antibodies among women attending antenatal and gynecology clinics in Sana'a City-Yemen.

Table 2 also shows that the seroprevalence of HSV IgM was $2.6 \%, 2.2 \%$ and $2.9 \%$ among low, middle and high family sizes, respectively, $\mathrm{P}=0.9$. While the seroprevalence of HSV-1 IgG among different family sizes were similar, $\mathrm{P}=0.7$ (Table 2 ). The association of some risk factors with seroprevalence of HSV IgM and HSV-2 IgG is shown in (Table 3$)$. Statistically non-significant $(\mathrm{P}>0.05)$ association was found between all studied risk factors and seroprevalence of HSV IgM and HSV-2 IgG.

\section{Discussion}

Herpes Simplex Virus infection is prevalent worldwide, particularly among women of childbearing age. ${ }^{4}$ This study was carried out to determine the seroprevalence of HSV-1 and HSV-2 based on typespecific serological tests and the effect of some potential risk factors 
on the prevalence of HSV. The results of this study may help to understand the percentage of HSV infection in Yemen and draw the attention of gynecologists and health centers to the effect of HSV infection on women and neonates. Overall seroprevalence of HSV IgM was $2.5 \%, 99.4 \%$ for HSV- 1 IgG and $5.1 \%$ for HSV-2 IgG. These results were in agreement with studies performed in neighboring countries. ${ }^{5,6}$ In apparently healthy group (who had no HSV infection symptoms), the seroprevalence of HSV-1 IgG was $100 \%$ in this study which was similar to that reported in a study conducted in Syria in which HSV-1 IgG seroprevalence among healthy group was $95.3 \%$. In Saudi Arabia, HSV-1 IgG was 90\%. ${ }^{6}$ While in Netherlands it was $68 \%$ and in Japan it was $86 \%{ }^{7,8}$ In the present study, seroprevalence of HSV-1 IgG among STIP and HLP groups were $99.6 \%$ and $97.9 \%$, respectively. These results were in agreement with that of the Syrian study, in which the seroprevalence of HSV-1 IgG among STIP was $90.5 \%$ and among HLP was $100 \% .^{5}$ seroprevalence of HSV-1 IgG antibodies in neighboring countries and this study were somewhat similar but they were low in Netherlands and Japan studies. ${ }^{7,8}$ This is probably because of the reduction of HSV-1 acquisitions in infancy due to better hygienic conditions and fewer family members. The high seroprevalence of HSV-1 IgG in Arab countries and this study probably due to extensive infant salivary spread in poor hygienic conditions. ${ }^{6}$ Overcrowding and close contact as part of the social structure in Yemen and neighboring countries play a major role in the transmission of HSV-1. In this study, seroprevalence of HSV-2 IgG among apparently healthy group was $6.2 \%$, which was similar to that reported in a study which conducted in Turkey (6.9\%). ${ }^{9}$ However, these results were lower than those of other studies, where HSV-2 IgG prevalence was 27.1\% in Saudi Arabia. ${ }^{10} 11.3 \%$ in Australia ${ }^{11}$ and $20 \%$ in United States. ${ }^{12}$ These could be due to the fact that most genital herpes infections by HSV-2 are asymptomatic but found positive by serological tests. ${ }^{13,14}$ So these women, who had been reported in this study as apparently healthy, might be infected asymptomatically or had past infections. In the current study, HSV-2 IgG in HLP was 8.3\%; which was higher than that of the Syrian study $(0 \%),{ }^{5}$ this may be due to that most HLP in Syrian study were at the mean age of 20 years old and most of them were unmarried. ${ }^{5}$ And HLP group in our study may have past infections with HSV-2 and were apparently healthy in clinical examinations. The seroprevalence of HSV-2 IgG among STIP was $4.3 \%$ which was less than that reported in an Egyptian study $(6.7 \%) .{ }^{15}$ However, higher prevalences were found in United Kingdom $(38 \%)^{16}$ in Tanzania (34\%). ${ }^{17}$ In Sweden $(40 \%)^{18}$ and in Netherlands $(30 \%) .^{7}$ These differences are probably due to the differences in sexual practices among these cultures. The seroprevalence of HSV IgM among healthy group in this study was $6.3 \%$; which was similar with that of the Syrian study (7.3\%), HLP group were all negative for HSV IgM in this study. This result was different from that of the Syrian study $(2.7 \%)$. In STIP group, the seroprevalence was $2.6 \%$ which was lower than that of the study in Syria (14.2\%). ${ }^{5}$ These differences could be attributed to the fact that IgM antibodies requires 10 days to be developed after the exposure and last only 7-10 days. Patients may present before or after this time interval, making the test relatively impractical. ${ }^{19} \mathrm{HSV}-1 \mathrm{IgG}$ prevalence in pregnant and non-pregnant women were $98.1 \%$ and $99.6 \%$, respectively which were similar to other studies that were conducted in other places in the world among pregnant women, $90.9 \%$ in Saudi Arabia. ${ }^{10} 96.9 \%$ in Kuwait ${ }^{20} 90 \%$ in Turkey $^{21}$ and $90 \%$ in Italy. ${ }^{22}$ In the current study, seroprevalence of HSV-2 IgG among pregnant women and non-pregnant women were $1.9 \%$ and $5.9 \%$, respectively. These results were similar to those reported in other studies in Egypt and Syria. ${ }^{5,14}$ Pregnant women were all negative for $\operatorname{IgM}$, while the seroprevalence of $\operatorname{IgM}$ among nonpregnant women was $3.1 \%$. Studies conducted among pregnant women revealed higher seroprevalence, $11.3 \%$ in Turkey and $6.7 \%$ in
Italy. ${ }^{9,23}$ High HSV-2 IgG seroprevalence in these studies could be due to the fact that pregnancy leads to alter genital tract physiology and depressed cell mediated immunity, which is important for control of viral infections. ${ }^{24}$ While in this study, the results were different and showed high seroprevalence of HSV IgM and HSV-2 IgG among nonpregnant women that could be due to small sample size of pregnant women. In the present study, the relations between prevalence of HSV antibodies and some social and clinical data were studied. The study showed increased of HSV-2 IgG in age group 25-35 years old, however, a statistically non-significant association was found between HSV seroprevalence and age of the studied women. These results were in agreement with other studies. ${ }^{5,25}$ However, a study reported by Tideman et al. ${ }^{26}$ found that HSV prevalence increases with age. In that study, women with more than one lifetime sexual partner were twice as likely to have HSV-2 antibodies than those women who delayed sex until they were 24 or over were $70 \%$ less likely to have antibodies to HSV-2 than those who commenced sexual activity at 15 or younger. ${ }^{26}$ These finding differ than our study due to different cultures. In this study, the seroprevalence of HSV-2 IgG was higher among married women than non-married women, this result was in agreement with other studies; in Egypt the seroprevalence of HSV-2 IgG in married women was $6.7 \%$ while in single women it was $0 \%{ }^{14}$ and in Zimbabwe, the prevalence of HSV-2 IgG in married and non-married women were $54.3 \%$ and $14.4 \%$, respectively. ${ }^{27}$ These results confirm that HSV-2 among married women is sexually transmitted. In the present study, the high HSV seroprevalence were found in women at middle and low educational level, but the relation between HSV antibodies and educational level was statistically non-significant. These results were similar to other studies, which indicated that HSV seroprevalence increases among women with low educational level. This due to that women with low educational level have had low knowledge about hygiene, safer sex and treatment in comparison with women with high educational level. ${ }^{28,29}$ In this study, a statistically non-significant association was found between residence and prevalence of HSV antibodies, which was in agreement with other studies. $^{30,31}$ In the current study, seroprevalence of HSV IgM and HSV-1 IgG were similar in all family size. That could be due to HSV1 can transmitted easily in childhood and all studied women had past infection with HSV-1. HSV IgM seroprevalence was similar in both groups of women that had or had not a history of abortion, however, HSV-2 IgG was higher in women with a history of abortion, but it was statistically non-significant. A similar finding was reported which showed a non-significant association between HSV and abortion. ${ }^{30} \mathrm{~A}$ study by Sisakis et al. ${ }^{32}$ mentioned that serological assays were not very useful for the elucidation of the role of HSV in inducing spontaneous abortions. Many studies mentioned that HSV-2 could be a risk factor in abortion; however, the detection of HSV-2 was in a small number comparing to the total studied women with history of abortion which does not support HSV infection as a major abortionrelated factor. In the present study, blood transfusion showed statistically non-significant association with HSV-2 seroprevalence. This result was in agreement with another study ensuring the fact that transmission of HSV-2 by blood transfusion-if occurring at all- is extremely rare event and the main rout of HSV-2 transmission is by sexual contact. ${ }^{33}$ In the present study, a statistically non-significant association was found between HSV seroprevalence and contraceptive used. This was in agreement with a study conducted in Italy. ${ }^{24}$ but different result was found in North America which indicated an increase of HSV-2 IgG among women used hormonal contraceptive. ${ }^{23}$ Using exogenous hormones may result in a complete suppression of endogenous progesterone cycling, which leads to increase the susceptibility of women to HSV infection. ${ }^{23}$ 
Table I Distributions of subjects according to general characteristics $(n=3 \mid 5)$

\begin{tabular}{lll}
\hline Characteristics & Subjects & \\
Age & No. & $\%$ \\
\hline I4- 24 & 108 & 34.3 \\
$25-35$ & 135 & 42.9 \\
$36-46$ & 60 & 19 \\
$>46$ & 12 & 3.8 \\
Marital Status & & \\
Single & 8 & 2.5 \\
Married & 307 & 97.5 \\
Residency & & \\
Urban & 235 & 74.6 \\
Rural & 80 & 25.4 \\
Educational Level & & \\
University/ Higher & 22 & 7 \\
Basic /Secondary & 167 & 53 \\
Illiterate & 126 & 40 \\
Clinical Diagnosis & & \\
STIP & 235 & 74.6 \\
HLP & 48 & 15.2 \\
Healthy & 32 & 10.2 \\
Pregnancy* & & \\
Pregnant & 53 & 17.3 \\
Non-pregnant & 254 & 82.7 \\
\hline
\end{tabular}

STIP: Sexual Transmitted Infected Patients,

HLP: Herpes Labial Patients.

*Among married women $(n=307)$

Table 2 Disturbance of HSV IgM and HSV-I \& 2 IgG according to soci-demographical characteristics $(n=3 \mid 5)$

\begin{tabular}{|c|c|c|c|c|c|c|c|c|c|c|c|}
\hline \multirow{2}{*}{ Category } & \multicolumn{2}{|c|}{ Subjects } & \multicolumn{3}{|c|}{$\lg M * *$} & \multicolumn{3}{|c|}{ HSV-I IgG } & \multicolumn{3}{|c|}{ HSV-2 IgG } \\
\hline & No. & $\%$ & NO. & $\%$ & $P *$ & No. & $\%$ & $P *$ & NO. & $\%$ & $\mathbf{P} *$ \\
\hline \multicolumn{12}{|l|}{ Pregnancy\# } \\
\hline Pregnant & 53 & 17.3 & 0 & 0 & \multirow{2}{*}{0.2} & 52 & 98.1 & \multirow{2}{*}{0.3} & 1 & 1.9 & \multirow{2}{*}{0.2} \\
\hline Non- Pregnant & 254 & 82.7 & 8 & 3.1 & & 253 & 99.6 & & 15 & 5.9 & \\
\hline \multicolumn{12}{|l|}{ Clinical Diagnosis } \\
\hline STIP & 235 & 74.6 & 6 & 2.6 & \multirow{3}{*}{0.2} & 234 & 99.6 & \multirow{3}{*}{0.3} & 10 & 4.2 & \multirow{3}{*}{0.29} \\
\hline HLP & 48 & 15.2 & 0 & 0 & & 47 & 79.9 & & 4 & 8.3 & \\
\hline Apparently healthy & 32 & 10.2 & 2 & 6.3 & & 32 & 100 & & 2 & 6.2 & \\
\hline \multicolumn{12}{|l|}{ Age } \\
\hline $14-24$ & 108 & 34.3 & 0 & 0 & \multirow{4}{*}{0.1} & 108 & 100 & \multirow{4}{*}{0.6} & 5 & 4.6 & \multirow{4}{*}{0.08} \\
\hline $25-35$ & 135 & 42.9 & 5 & 3.7 & & 134 & 99.3 & & 11 & 8.1 & \\
\hline $36-46$ & 60 & 19 & 2 & 3.3 & & 59 & 98.3 & & 0 & 0 & \\
\hline$>46$ & 12 & 3.8 & 1 & 8.3 & & 12 & 100 & & 0 & 0 & \\
\hline \multicolumn{12}{|l|}{ Marital Status } \\
\hline Single & 8 & 2.5 & 0 & 0 & \multirow{2}{*}{0.6} & 8 & 100 & \multirow{2}{*}{0.8} & 0 & 0 & \multirow{2}{*}{0.5} \\
\hline Married & 307 & 97.5 & 8 & 2.6 & & 305 & 99.3 & & 16 & 5.2 & \\
\hline \multicolumn{12}{|l|}{ Educational Level } \\
\hline University/Higher & 22 & 7 & 0 & 0 & \multirow{3}{*}{0.6} & 22 & 100 & \multirow{3}{*}{0.2} & 1 & 4.5 & \multirow{3}{*}{0.4} \\
\hline Basic/ Secondary & 167 & 53 & 4 & 2.4 & & 167 & 100 & & 11 & 6.6 & \\
\hline Illiterates & 126 & 40 & 4 & 3.1 & & 124 & 98.4 & & 4 & 3.1 & \\
\hline \multicolumn{12}{|l|}{ Residency } \\
\hline Urban & 235 & 74.6 & 6 & 2.5 & \multirow{2}{*}{0.9} & 233 & 99.2 & \multirow{2}{*}{ I } & 14 & 5.9 & \multirow{2}{*}{0.2} \\
\hline Rural & 80 & 25.4 & 2 & 2.5 & & 80 & 100 & & 2 & 2.5 & \\
\hline Family Size & & & & & & & & & & & \\
\hline $2-5$ & 76 & 24 & 2 & 2.6 & & 76 & 100 & & & & \\
\hline $6-9$ & 135 & 43 & 3 & 2.2 & 0.9 & 134 & 99.3 & 0.7 & Not $\mathrm{t}$ & & \\
\hline$>9$ & 104 & 33 & 3 & 2.9 & & 103 & 99 & & & & \\
\hline
\end{tabular}

$* P=$ Probability value $(P>0.05=$ Non- significant, $P \leq 0.05=$ Significant $)$,

**IgM includes both HSV-I and HSV-2,

\#Among married women $(n=307)$.

Citation: Assayaghi RM,Al-Jaufy AY,Al-Robasi AA. Seroprevalence and risk factors for herpes simplex virus type I and 2 among women attending antenatal and gynecology clinics in Sana'a City-Yemen.J Hum Virol Retrovirol. 2017;5(4): I-6. DOI: I0. I5406/jhvrv.20I7.05.00 I63 
Table 3 Risk factors for HSV-2 seroprevalence $(n=3 \mid 5)$

\begin{tabular}{|c|c|c|c|c|c|c|c|c|c|c|c|}
\hline \multirow{4}{*}{ Test Results } & \multirow{4}{*}{ Risk Factors } & \multicolumn{9}{|c|}{ Antibody } & \multirow{4}{*}{$P *$} \\
\hline & & $\lg M$ & & \multirow{2}{*}{\multicolumn{2}{|c|}{ Negative }} & \multirow{3}{*}{$P *$} & \multirow{2}{*}{\multicolumn{2}{|c|}{$\begin{array}{l}\text { HSV-2 IgG } \\
\text { Positive }\end{array}$}} & \multirow{2}{*}{\multicolumn{2}{|c|}{ Negative }} & \\
\hline & & \multicolumn{2}{|c|}{ Positive } & & & & & & & & \\
\hline & & No & $\%$ & No & $\%$ & & No & $\%$ & No & $\%$ & \\
\hline \multirow{2}{*}{ Contraceptive use } & Yes & 6 & 3.5 & 166 & 69.5 & \multirow{2}{*}{0.2} & 9 & 5.2 & 163 & 94.8 & \multirow{2}{*}{0.08} \\
\hline & No & 2 & 1.4 & $|4|$ & 98.6 & & 7 & 4.9 & 136 & 95.1 & \\
\hline \multirow{2}{*}{ History of abortion } & Yes & 3 & 3.2 & 90 & 96.8 & \multirow{2}{*}{0.6} & 6 & 6.5 & 87 & 93.5 & \multirow{2}{*}{0.4} \\
\hline & No & 5 & 2.2 & 217 & 97.8 & & 10 & 4.5 & 212 & 95.5 & \\
\hline \multirow{2}{*}{ History of Blood transfusion } & Yes & 0 & 0 & II & 100 & \multirow{2}{*}{0.1} & I & 9.1 & 10 & 90.9 & \multirow{2}{*}{0.5} \\
\hline & No & 8 & 2.6 & 296 & 97.4 & & 15 & 4.9 & 10 & 95.1 & \\
\hline
\end{tabular}

$* P=$ Probability value $(P>0.05=$ Non- significant, $P \leq 0.05=$ Significant $)$.

**IgM includes both HSV-I and HSV-2.

\section{Conclusion and recommendation}

It can be concluded from this study that the prevalence of HSV-1 antibodies is higher than HSV-2. The prevalence of HSV-2 antibodies is lower than those reported in other studies, which is probably due to the differences in sexual practices among these cultures. Overcrowding and poor hygiene could be connected to the high prevalence of HSV-1 in Yemen. Type specific serological tests of HSV helping identifying the infection; therefore doctors should request these tests for all suspected patients. The risk factors attributed to the seroprevalence of HSV among pregnant women are not clear in Yemen, therefore further studies are required.

\section{Acknowledgments}

None.

\section{Conflicts of interest}

None.

\section{References}

1. Lawrence WD. Sherris's Medical Microbiology (4th edn). In: Kenneth JR \& George C (Eds.), Herpesviruses, McGraw-Hill, USA, pp. 2004;555-576.

2. Rhoda LA. Laboratory diagnosis of viral infections ( $3^{\text {rd }}$ edn). In: Dwin HL \& Smith T (Eds.), Herpes Simplex Viruses types 1 and 2, Marce Dekker INC, USA, pp. 1999;489-513.

3. Howley RH, Kinp DH. Field's Virology ( $4^{\text {th }}$ edn). In: Roizman B \& Pellett PE (Eds.), Herpesviridae, USA, pp. 2001;2381-2397.

4. Riley LE. Herpes Simplex Virus. Semin Perinatol. 1998;22(4):284-292.

5. Ibrahim AI, Kouwatli KM, Obed MT. Frequency of herpes simplex virus in Syria based on type-specific serological assay. Saudi Med J. 2000;21(4):355-360.

6. Hossain AHerpes Simplex Virus type1 (HSV-1) and VaricellaZoster virus (VZV) infection in Saudi Arabia. $J$ Trop Pediart. 1989;35(4):171-174.

7. Roest RW, van der Meijden WI, van Dijk G, et al. Prevalence and association between HSV-1 and HSV-2 specific antibodies in attendees in sexual transmitted disease clinic. Int J Epidemiol. 2001;30(3):580-588.

8. Hashio M, Lee KF, Nahmias JA, et al. An epidemiologic study of herpes simplex virus type 1 and type 2 infections in Japan based on type specific assay. Epidemiol Infect. 1998;120(2):179-186.

9. Duran N, Yarkin F, Evruke C, et al. Asymptomatic Herpes Simplex Virus type-2 (HSV-2) infection among pregnant women in Turkey. Indian $J$ Med Res. 2004;120(2):106-110.

10. Hani OG, Telmesan AM, Mahomed MF. TORCH agent in pregnant Saudi women. Med Princ Pract. 2002;11(4):180-182.

11. Gottlieb SL, Douglas JM, Foster M, et al. Incidence of Herpes Simplex Virus type 2 infections in 5 sexually transmitted disease(STD) clinics and effect of HIV/STD risk-reduction counseling. $J$ Infect Dis. 2004;190(6):1059-1067

12. Bassett I, Donovan B, Boodsworth NJ, et al. HSV-2 infection of heterosexual attending a sexual health center. Med J. 1994;160:697-700.

13. Paz-Bailey G, Ramaswamy M, Hawkes SJ, et al. Herpes simplex Virus type 2 increasingly in developing countries. Sex Transm Infect. 2007;83(1):16-22.

14. DeNoon DJ. Genital Herpes Silent Spread Even Without Sores, Genital Herpes Carriers Infectious 10\% of the Time. WebMed Magazine. 2011.

15. Ibrahim OA. Seroprevalence study of HSV-2 in female in childbearing period. Ain Shams University, Egypt. 1998.

16. Ramasway M, Mc Donald CM, Sabin CG, et al. The epidemiology of genital infection with Herpes simplex type 1 and type 2 in genitourinary medicine attendees in inner London. Sex Trans Infect. 2005;81:306-308.

17. Langeland N, Haarr L, Mhalu F. Prevalence of HSV-2 antibodies among STD clinic patients in Tanzania. Int J STD AIDS. 1998;9(2):104-107.

18. Rsgren M, Skocy E, Jeanson S, et al. Prevalence of HSV-2 in pregnant women in Stockholm in 1969, 1993 and 1989. Int $J$ STD and AIDS. 1994;5:113-116

19. Page J, Taylor J, Tideman RL, et al. Is HSV serology useful for first episode genital herpes? Sex Transm Infect. 2003;79:276-279.

20. Al-Nakib W, Ibrahim ME, Hathout H, et al. Seroepidemiology of viral and toxoplasmal infections during pregnancy among Arab women in of childbearing age in Kuwait. Int J Epidemiol. 1983;12(2):220-223.

21. Arseven G, Tuncel E, Tuncel S, et al. Distrbuation of HSV-1 and HSV-2 in pregnant women in Turkey. Mikrobiyol Bul. 1992;26(4):359-366.

22. Boselli F, Chiossi G, Bortolamasi M, et al. Prevalence and determination of genital shedding of Herpes Simplex Virus among women attending Italian colposcopy clinic. Eur J Obstet Gynecol Reprod Biol. 2005;118(1):86-90.

23. Suligoi B, Cusan M, Santopadre P, et al. Herpes simplex virus type 2 specific seroprevalence among various populations in Rome, Italy. Sex Transm Infect. 2000;76(3):213-214.

24. Mostad SB, Kreiss JK, Ryncarz AJ, et al. Cervical shedding of Herpes Simplex Virus in HIV infected women: effect of hormonal contraceptive, pregnancy and vitamin A deficiency J Infect Dis. 2000;181(1):58-63.

25. Obasi A, Mosha F, Quigley M, et al. Antibody to HSV-2 as a marker of sexual risk behavior in rural Tanzania J Infect Dis. 1999;179(1):16-24.

26. Tideman RL1, Taylor J, Marks C, et al. Sexual and demographic risk factors for HSV-1 and HSV-2 in women attending an antenatal clinic. Sex Transm Inf. 2001;77(6):413-415. 
27. Mc Farland W, Gwanzura L, Bassett MT, et al. Pervalence and incidence of Herpes Simplex Virus type 2 infections in Zimbabween. J Infect Dis. 1999;180(5):1459-1465.

28. Kebede Y, Dorigo-Zetsma W, Mengistu Y, et al. Transmission of Herpes Simplex Virus type 2 among factory in Ethiopia. J Infect Dis. 2004;190(2):365-372.

29. Smith JS, Herrero R, Muñoz N, et al. Prevalence and risk factors of HSV-2 infection among women at middle age in Brazil and Philippines. Sex Transm Dis. 2001;28(4):187-194.

30. Cunningham AL, Taylor R, Taylor J, et al. Prevalence of infection with HSV-1 and HSV-2 in Australia. Sex Transm Infect. 2006;82(2):164-168.
31. Maritra N, Gupta M. Seroprevalence and correlates of HSV-2 infection in a general gynecology clinic. Arch Gynea Obstet. 2007;257(1):19-23.

32. Sifakis S, Koumantakis E, Koffa M, et al. Detection of Herpes Simplex Virus in aborted material using PCR technique. Gynecol Obstet Invest. 1998;45(2):109-115.

33. Kühn JE. Transfusion associated infections with cytomegalovirus and other human herpesviruses. Infusionsther Transfusionsmed. 2000;27(3):138-143. 